\title{
Role of Learning Analytics to Evaluate Formative Assessments: Using a data driven approach to inform changes in teaching practices
}

\author{
Rayapudi Hima sagarika ${ }^{1}$, Dr. Rohit Kandakatla ${ }^{2,3}$, Ashwini Gulhane ${ }^{1}$ \\ ${ }^{1}$ Department of CSE - KG Reddy College of Engineering \& Technology, \\ ${ }^{2}$ Department of ECE - KG Reddy College of Engineering \& Technology, \\ ${ }^{3}$ Center for Engineering Education Research, KLE Technological University, \\ 1 sagarika.rayapudi@gmail.com \\ 2rohit.kandakatla@kgr.ac.in
}

\begin{abstract}
One of the most challenging tasks for faculty in their role as a teacher is to design, administrate, and evaluate formative assessments. This results in a lot of faculty not utilizing the formative assessments as a form of student feedback and make regular changes to the course. In this study, we explore the role of technology in helping faculty implement and analyze formative assessments. We believe the advancement of technology and its increasing applications in education may result in development of novel solutions to this impediment through learning analytics. This paper explores the use of such data analytics to address the challenges impeding the capacity of instructors to provide personalized feedback at scale.
\end{abstract}

The study was implementing in the Computer Science and Engineering Department where a group of faculties who teach undergraduate engineering students. The faculty designed and administered a set of formative assessments in multiple courses through the learning management system. The data collected from the formative assessments was analyzed using learning analytics and the results were used to provide actionable recommendations that could better support students to achieve the learning outcomes of the course. The data was analyzed to understand and optimize the learning process of the students in the course. The results of the paper will provide insights to engineering educators on how they could take a data driven approach and harness the power of technology to better support their students. This approach will also help direct students towards deeper and self-regulated learning.

Keywords: Learning Analytics, Formative assessments, Canvas, Data driven approach.

\section{Corresponding Author}

\section{Rayapudi Hima sagarika}

Department of CSE

KG Reddy College of Engineering \& Technology

sagarika.rayapudi@gmail.com

\section{Introduction}

Increasing motivation, autonomy, effectiveness, and efficiency of learners and teachers is an important driver for learning analytics research (Buckingham et al., 2012). Technology has seen an increase in its usage in higher education for the last 10 years, however the use of technology for assessment purpose has been minimal. Most of the faculty use educational technology for the effective content delivery but somehow failed to utilize them for creation, implementation, and evaluation of assessments. The use of technology especially for formative assessments would be highly useful to faculty as the facilitation and evaluation of formative assessments is a time-consuming task. Most faculty therefore don't end up conducting formative assessment even though they help provide necessary feedback to identify students' pre-conceptions, misconceptions, and other challenges they're encountering in the course. The challenge of time consumed to facilitate and evaluate formative assessments can be solved through the usage of educational technology tools. We therefore try and understand how the affordances of technology could be utilized to help faculty implement and evaluate formative assessments and use the results to support students in the course.

The disruptions caused by the COVID19 pandemic forced all higher education institutions to switch to an online mode of delivery. This meant that the assessments required to be designed, administered, and evaluated online. While faculty can plan and administer summative assessments outside the regular online classes, they may find it challenging to facilitate formative assessments synchronously during live online lecture hours. As Vonderwell, Liang, and Alderman (2007) indicated, assessment (whether formative or summative) in online learning contexts encompasses distinct characteristics as compared to face to face contexts, particularly due to the asynchronous nature of interactivity among the teacher and the students. Hence, it requires the faculty to rethink how they could effectively administer formative assessments during online classes in order to support meaningful higher-order or deep learning among the students. Another common challenge that faculty encounter is time needed to evaluate formative assessments. To address this challenge, learning analytics can be utilized to investigate the possibility using analytics to evaluate the formative assessments and use the results to understand how better to support students in their learning process (Naif et al., 2013). 
In this paper, we explore the possibility of how learning analytics and formative assessments could use together to provide immediate and personalized feedback to students. For an effective teaching and learning process, learning analytics can be used to analyzing the data collected from the students in the form of formative assessments. Learning analytics can be used by applying the AI/ML algorithms through regression models to predict the future analytics for the data. This paper focuses on the data collected through formative assessments from the students who were taking Computer Science and Engineering courses at KG Reddy College of Engineering\& Technology. We address two specific research questions in this study:

RQ1: How can technology tools be aligned to assessments to implement formative assessments during online mode of teaching?

RQ: How can learning analytics be used to analyze formative assessments in undergraduate engineering courses?

\section{Literature Review}

\subsection{Formative Assessments in Engineering Education}

Assessments are often a collection of data which could be used to measure the student's skill, attitude and learning. It is majorly classified into two types

i) Summative: They are used for grading purpose at the end of the semester and can also be defined as "assessment of learning".

ii) Formative: They are used to give feedback and not to grade them and are also defined as "assessment for learning".

Formative assessments are used as a means to provide feedback to both the teachers and the students during the learning process, for example, diagnostic assessment or testdirected assessments. Feedback would be most effective when it is related to learning goals, hence formative feedback will be most effective when it is not only focused on monitoring the progress towards a specific goal but also when it provides timely feedback to the students. These processes characterize formative assessment and are aimed to support student learning. Formative assessments should therefore be aligned with the pedagogy to administer the learning process and later modifying the content delivery based on the results of the assessment. However, formative assessment may fail to improve the teaching learning process if the data collected through the assessment send up being improperly utilized. The formative assessment may also inform other stakeholders such as institutions, parents, employers and the wider community about learner's progress (Smith, 2007) and has a positive impact when the data collected is converted into valuable feedback.

\subsection{Learning Analytics in Education}

The use of technology to better understand how learning occurs has received considerable attention in the last 10 years, even breaking into specialized subfields such as learning analytics and educational data mining (Greller \&Drachsler, 2012). However, educators have reported challenges that have emerged due to the advancement in the use of technology-based assessments. For instance, educators report having overwhelmingly large amounts of data from different sources (i.e., heterogeneous data), and not being able to access data with enough time to improve instruction (Vieira, 2008). As a research and teaching field, learning analytics sits at the convergence of Learning (e.g. educational research, learning and assessment sciences, educational technology), Analytics (e.g. Statistics, visualization, computer/data sciences, artificial intelligence), and Human-Centered Design (e.g. usability, participatory design, sociotechnical systems thinking). Higher education leaders have recognized the value of learning analytics for improving not only teaching and learning but also the entire educational arena (Ifenthaler et al., 2014)

Learning analytics collects and analysis data generated by learners during their interaction in online and offline environments. The data is used to optimize the learning and make decisions. The data can be of any kind, it can be log data, prior learning experiences, learning abilities, etc. Learning analytics can be implemented for the students and by the faculty to identify the learning difficulties and providing the learning support. It is most commonly used by teachers to identify learning difficulties for improvement of curriculum design and give support to the learners. Learning analytics is fundamentally used to empower learners by enhancing their control of learning decisions.

\subsection{Formative Assessments through Technology}

When the sudden transition from in-person to online teaching took place due to COVID19, all the faculty were focused on teaching their courses online. Along with the teaching, the assessments need to be conducted online either in asynchronous or synchronous mode. But it has been a long-time challenge to design and administer the formative assessments effectively using technology. The convergence of formative assessment with technological perspectives brings to life the concept of online formative assessment. In describing this convergence, Pachler et al. (2010) used the term formative e-assessment which they defined as "the use of ICT to support the iterative process of gathering and analyzing information about student learning by teachers as well as learners and of evaluating it in relation to prior achievement and attainment of intended, as well as unintended learning outcomes"(p. 716). The Pachler et al.'s definition encompasses application of formative assessment in all forms of e-learning environments including the complementary role of ICT in face to face settings as well as in blended and online learning settings. In the same vein, we define online formative assessment as the application of formative assessment within learning online and blended settings where the teacher and learners are separated by time 
and/or space and where a substantial proportion of learning/teaching activities are conducted through webbased ICT.

There are many issues in design and administration of assessments online. These issues include validity, reliability and dishonesty. In the online mode of teaching, these issues take on new dimensions in various ways due to the nature of interactivity in online environments among students and the teacher (Oosterhof et al., 2008, pp. 76-77; Wolsey, 2008). Faculty in the online mode have the flexibility to conduct formative assessments in the asynchronous or synchronous mode.

Asynchronous mode of formative assessments allows the students to think and self-evaluate their work before submitting it to the instructors or peers (in case of peer evaluation). Examples of asynchronous assessments include discussions, descriptive assignments, MCQs, case study demonstrations, problem solving exercises. All these formative assessments give students an adequate time to compose and submit. Discussion threads can be used for online assessments which can be graded with points or ungraded with valuable feedback. Many of the Learning Management Systems (LMS's) provide options for creating such discussions. The discussions can be individual or within the group. Online submission of the descriptive assignments can be created in the LMS through submitting the text or uploading a document. Similarly, MCQs can also be used as online assessments through LMS or using Google forms with timers.

Synchronous assessments are considered to be an effective way of evaluating the students learning process while the lectures are delivered in the video conferencing mode. The assessments conducted in synchronous mode gives immediate feedback to assess the students. Few of the assessments in the synchronous mode are polling, random questioning through random number generators, presentations by the students through screen sharing options, etc. Every video conferencing tool has a polling option which can be used at regular intervals to create interest and post questions to the students and the response can be collected immediately with meaningful interactions. However, Oosterhof et al. (2008, pp. 76-77) cautioned that, although integration of formative assessment in online environments can potentially offer enhanced interactivity, the design of these environments is critical because formative assessment requires additional design considerations from the outset in order to provide facilities that can foster its effective integration. Hence design and implementation of the formative assessments in online is very important. Also briefing about the assessments to the students and proper reasoning helps in providing proper feedback. Chung et al. (2006) illustrated how online formative feedback provided opportunities for scaffolding learning towards higher levels of achievement.

\subsection{Learning analytics for formative assessments}

Feedback obtained by all the formative assessments can be collected, analyzed and utilized for improving the learning process through timely feedback. The goal of formative assessment is to monitor student learning to provide ongoing feedback that can be used by instructors to improve their teaching and by students to improve their learning. More specifically, formative assessments, help students identify their strengths and weaknesses and target areas that need work, help faculty recognize where students are struggling and address problems immediately.

The reason behind using both learning analytics and formative assessments methods together was to provide immediate and detailed feedback. "Assessment alone changes very little; likewise, learning analytics cannot act alone in radically disrupting and transforming education. Assessment (when done well) is about the authentic and deep understanding and improvement of teaching and learning (Booth M., 2012). Analytics is about using the power of information technology to see patterns of success (or failure) in learning. Combining the two might actually produce the seeds of transformation - a powerful inquiry into what supports authentic, deep, transformative learning for students.

\section{Methodology:}

This paper presents a study on the alignment of technology with formative assessments during the online mode of teaching and the use of learning analytics. Faculty teaching courses for computer science and engineering have been involved in this study in the design and implemented the formative assessments for their respective courses. Learning analytics is used to analyze the data and the results produced are used as recommendations to enhance the students learning. Learning analytics is done in four phases. They are Measuring, Collection, Analysis and Reporting of the data

1. Measuring: In this phase measuring was done by conducting formative assessments in the selected courses. This assessment helps to assess the students learning objectives. Here formative assessments were used to assess the students learning and provide constructive feedback and not to grade them. The assessments were designed and implemented using CANVAS Learning Management System. The tabular form table (i) shows the formative assessments conducted for the courses taught by the faculty. A data of 30 students were taken for the study. All the formative assessments were implemented and administered online.

2. Collection: After implementation and administering the formative assessments, the data is collected from CANVAS grade sections. There was a need to verify the quality of data collected because the data transferred from one place to another through transmission channel might have issues like noise (data mismatches), missing of data, outliers or duplication of data. To avoid this data cleaning is recommended. This is done by using data mining. Data mining is a process used to turn raw data into useful information. 


\begin{tabular}{|c|c|c|}
\hline $\begin{array}{l}\text { Course } \\
\text { Name }\end{array}$ & $\begin{array}{l}\text { Type of Formative } \\
\text { Assessment }\end{array}$ & Purpose of Formative Assessment \\
\hline \multirow[b]{2}{*}{$\begin{array}{l}\text { Data } \\
\text { Analytics }\end{array}$} & Graded Discussion & $\begin{array}{l}\text { As Data Analytics play a vital role in present scenario it is very important for the students to learn the } \\
\text { Course from the basics. So, a discussion was conducted for the students after the class to know how well } \\
\text { they have understood the course content by initiating session of open-ended question with them. }\end{array}$ \\
\hline & Self-recorded Video & $\begin{array}{l}\text { The instructor could observe whether the students were working in the context of teamwork or individual } \\
\text { assignments, students are required to demonstrate about the given topic and assignments follow } \\
\text { assessment criteria and assessment rubric to connect course materials, readings, and independent } \\
\text { research to address a problem by critically engaging, reflecting, evaluating, and presenting their own } \\
\text { analysis and view on the course. }\end{array}$ \\
\hline $\begin{array}{l}\text { Computer } \\
\text { Networks }\end{array}$ & Quiz & $\begin{array}{l}\text { This assessment would help faculty to test the student understanding of the structure and functions that } \\
\text { computer networks. As Computer network course had a lot of content and student could get confused in } \\
\text { identifying different network, models, and transmission modes, conducting the quiz would help assess } \\
\text { students' misconceptions in the course. }\end{array}$ \\
\hline $\begin{array}{l}\text { Software } \\
\text { Engineering }\end{array}$ & Case study & $\begin{array}{l}\text { Usually students work in teams and different teams may come up with different solutions. These } \\
\text { solutions are discussed by whole class. Here students may have to analyze various solutions and present } \\
\text { their views. Thus, discussions facilitate learning and communication skills. Sometimes students may be } \\
\text { asked to submit a detailed report of their solutions, which can be used for assessment. }\end{array}$ \\
\hline \multirow{2}{*}{$\begin{array}{l}\text { Distributed } \\
\text { Databases }\end{array}$} & Seminar & $\begin{array}{l}\text { To create interest about the course, seminar could be conducted and evaluate the student knowledge and } \\
\text { understanding. }\end{array}$ \\
\hline & Check list & Check list assessment can be done to avoid confusion for the students when they are writing the queries. \\
\hline \multirow{2}{*}{$\begin{array}{l}\text { Formal } \\
\text { Language } \\
\text { Automatic } \\
\text { Theory }\end{array}$} & Assignment & $\begin{array}{l}\text { Finite automata present the theoretical aspects of computer science, and helps define infinite language } \\
\text { in finite ways construct NFA for related problem so practicing is required for course by writing } \\
\text { assignment students can practice problems and decide whether a string is in language or not. }\end{array}$ \\
\hline & Short test & $\begin{array}{l}\text { Test can be conducted to avoid the Misconception and student can identify language for given NFA and } \\
\text { DFA by solving problems }\end{array}$ \\
\hline
\end{tabular}

Table (i) Types of formative assessments

Example with screenshot of one formative assessment implemented for the case study in software engineering course is shown in the Fig (i). The screenshot shows the CANVAS interface for one student

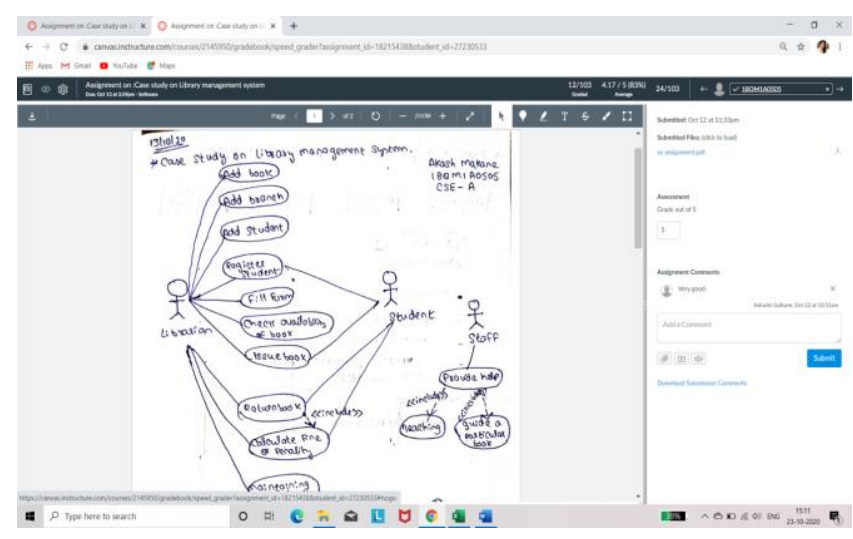

Fig (i) Implementation of Casestudy in CANVAS

WEKA tool is used to mine the data in this study. The collection of data involves two steps

A. The first step was to determine the data requirements for example course names, types of assessments, students roll numbers, performances. A spreadsheet was used for placing the entire data collected.

B. B. The data was then cleaned up before moving to the analysis. Data quality check can be done for removing noise, outliers, missing values, duplicate data, any errors using WEKA tool which is an open source.

The data set is hence formed. The data sheet produced in the study for various courses and assessments is shown in the below Fig (ii) 


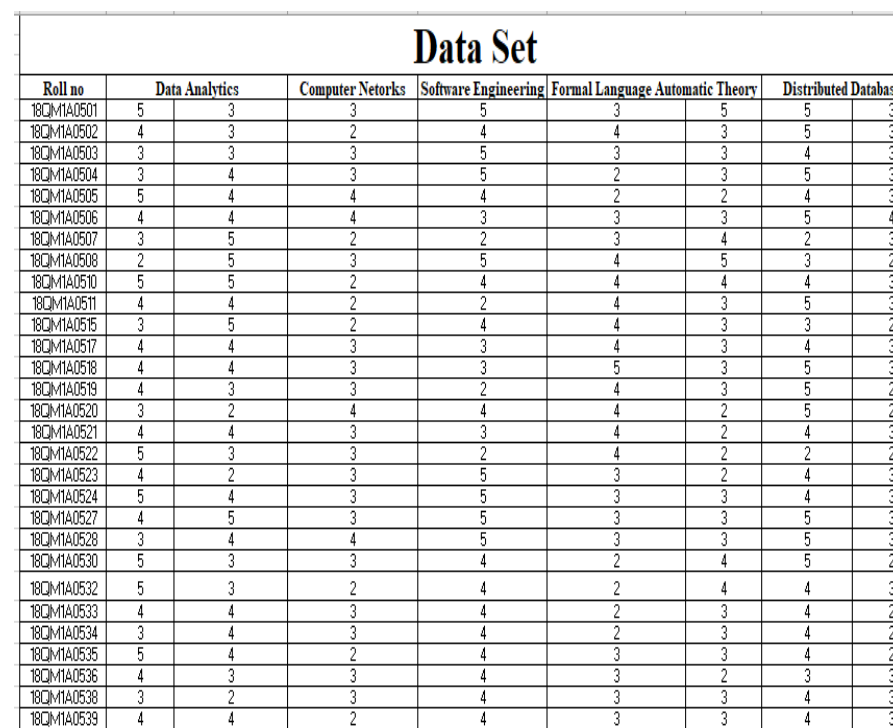

Fig (ii) Data Set for formative assessments

3. Analysis: In this stage, the data was analyzed to understand and optimize the learning process of the students in the courses by giving the constructive feedback. This approach will also direct the students towards deeper and self-regulated learning. In this study, the analysis of the data is done by taking the mean of the data available in the data sets. It is calculated student wise by using the below formula.

\section{Mean $(m)=$ Sum of the performance indicators in terms Number of terms}

Whereas term represents the type of formative assessments in the dataset. Performance indicators were the student grades represented in the form of data. The obtained result were used to identify the slow and fast learners and recommend action steps to improve their performance in the form of feedback.

4. Reporting of data: After obtaining the mean values of all the students for 8 terms regression technique is used from machine learning algorithms for the analytics. To apply regression technique, $y=m x+c$ formula is used. Where $\mathrm{m}$ is the slope of the line and $\mathrm{c}$ is an intercept. The slope line is determined by varying the values of $\mathrm{m}$ and $\mathrm{c}$. The regression model consists of dependent and independent variables which relate linearly to each other. Here the dependent variables are the student roll numbers whereas the independent variable are the performance levels of the students. Regression is a statistical method used to determine the strength and character of the relationship between one dependent variable (usually denoted by y) and a series of other variables (known as independent variables). The independent variable explains the other variables whereas dependent variables. Regression is used to represent the line of best fit that is represented by $\mathrm{y}=\mathrm{mx}+\mathrm{c}$. After applying the regression, the output is automatically tabulated in new excel sheet as summary output as shown in the Fig (iii)

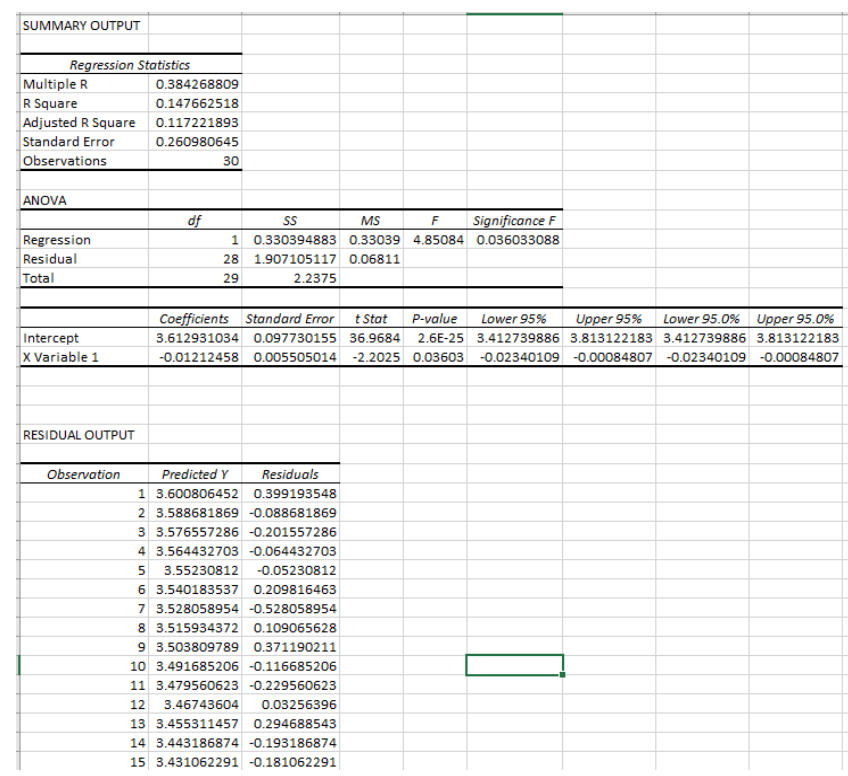

Fig (iii) Summary output for the analysis

The summary output represents the predicted values of the students' performance. With that analytics, slow and Advanced learners were identified based on the students' performance.

\section{Results and Discussion:}

After the completion of all the stages of learning analytics measuring, collecting, analysis, and reporting through regression technique, the graphical representation of predicted analysis is generated along with the summary output. The graphical representation is shown below in Fig (iv). In the below graph $\mathrm{X}$-axis Represents dependent variables (Roll numbers) and Y-axis represents independent variables (Performances in Formative assessments).

\section{$X$ VARIABLE 1 LINE FIT PLOT}

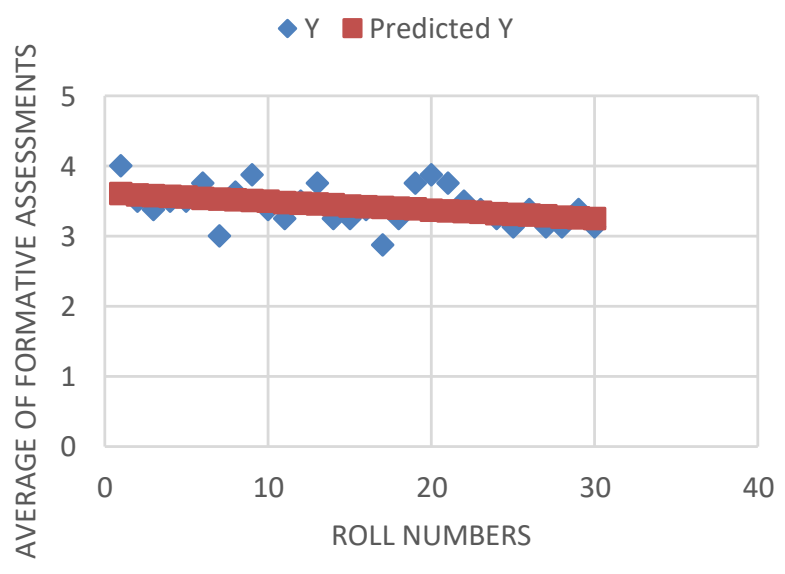


Fig (iv) Graphical representation for Predicted analytics

Based on the observations made from the above graph the slow and advanced learners are identified. The blue dots above and within the predicted line (orange colour line) represents the advanced learners whereas the dots below the predicted line represents the slow learners. Now these results were used to provide actionable recommendations that could better support students to achieve their learning outcomes. Few of the action steps recommended to enhance the students learning are given below:

\section{1 Action taken on the students results}

\section{Activities that support Advanced Learners}

- Data Analytics - Seminar was conducted on Data Science for future scope.

- Software Engineering - Guest Lecture by Industrialist on designing and implementation of an Application program interface.

- Computer network- Students have completed advanced courses on Computer Networks and Security through MOOC's (Coursera, NPTEL \& Spoken tutorial).

- Distribute Databases - Workshop with Hands-on session on ORACLE .

- Formal language automata theory- Expert lecture on Finite automation which is the pre-requisite for Artificial intelligence.

This study also shows the students action recommendation outputs in the form of students' engagements. A sample screenshot of the student presentation in the online mode is shown in the below Fig (v).

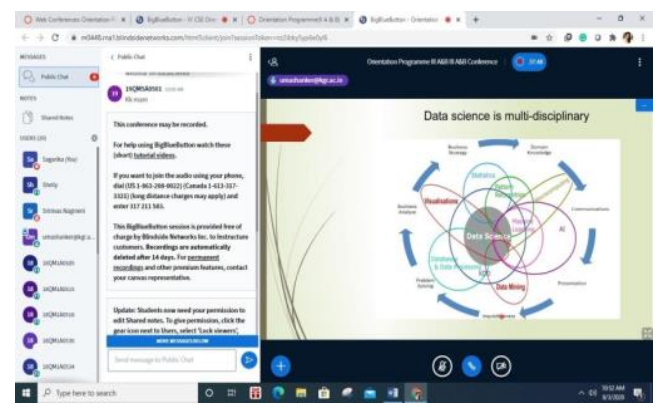

Fig (v) Seminar on Data Science for Advance learners

\section{Activities to support slow learners}

- $\quad$ Students groups were formed for peer-peer learning by implementing collaborative learning practices. CANVAS had the tools to conduct the collaborative activities online using breakout rooms.

- Individual counseling was done by concern subject teacher using the mentoring process.
- An additional lecture was schedule for every week for a course in the form a tutorial. Slow learners were given an opportunity in the tutorial hours to clarify their doubts regarding the course content. Tutorial classes are also utilized as remedial classes for the slow learners which help students to revise and increase their retention levels. A screen shot showing the tutorial classes is shown in the Fig (vi).

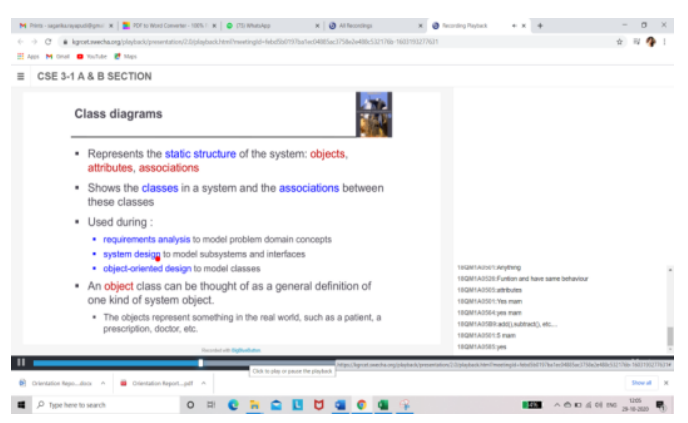

Fig (vi) Tutorial class conducted for Slow learner

\section{Conclusion:}

The aim of this research study is to report the results of the formative assessments designed, implemented and administered online using technology tool CANVAS. The performances are analyzed and predicted using learning analytics. The results are used to provide actionable recommendations to enhance learning and achieve outcomes of the course. Students can use this data to identify the gaps in their learning process whereas the faculty can use this data to change their teaching strategies in designing the curriculum and assessments both online and in-person. While the formative assessments in this study were used to identify slow and advanced learners, future studies will include the identification of gaps in slow learners. The identification of gaps will help faculty in providing specialized learning recommendations and resources. Formative assessments and learning analytics could therefore be used improve teaching and learning practices in engineering education and improve students' performance and retention.

\section{Acknowledgement:}

I would like to thank management of KG Reddy College of Engineering \& Technology for carrying out the research studies on engineering education to improve the teaching learning process. I would also like to thank Dr.Rohit Kandakatla, Director of the institution for continuous support in bringing the innovative practices in the teaching learning through scholarly research. And I extend my thanks to the Principal, Dr.R.S.Jahagirdar in providing opportunities and resources to conduct research. Finally, I 
would like to thank entire members of CEED for collaborative support.

\section{References:}

1. Buckingham Shum, S., Gašević, D., \& Ferguson, R. (Eds.). (2012). Proceedings of 2nd International Conference on Learning Analytics and Knowledge, LAK12. New York, NY: ACM.

2. Gijbels, D., Dochy, F., Bossche, P. V., \&Segers, M. (2005). Effects of problem-based learning: a metaanalysis from the angle of assessment.Review of Educational Research,75(1), 27-61

3. Greller, W., \&Drachsler, H. (2012). Translating learning into numbers: A generic framework for learning analytics. Educational technology \& society, 15(3), 42-57.

4. Ifenthaler, D., Widanapathirana, C. Development and Validation of a Learning Analytics

Framework: Two Case Studies Using Support Vector Machines. Tech Know Learn19, 221-240 (2014).

5. M. Booth. (2012). Learning Analytics: The new Black. Available: http://www.educause.edu/ero/article/learninganalytics-new-black

6. Naif, R.A., Hugh, C.D.(2013).“ Analytics and Formative Assessment to Provide Immediate Detailed Feedback Using a Student Centered Mobile Dashboard,"Seventh International Conference on Next Generation Mobile Apps, Services and Technologies, 2013

7. Oosterhof, A., Conrad, R. M., \& Ely, D. P. (2008).Assessing learners online. New Jersey: Pearson.

8. Pachler, N., Daly, C., Mor, Y., \&Mellar, H. (2010). Formative e-assessment: Practitioner cases.Computers\& Education, 54,715-721

9. Smith, G. (2007). How does student performance on formative assessments relate to learning assessed by exams?Journal of College Science Teaching, 36(7), 28-34.

10. Vieira C., Parsons P. \& Byrd V., Visual learning analytics of educational data:A systematic literature review and research agenda, Computers \& Education (2018)

11. Vonderwell, S., Liang, X., \& Alderman, K. (2007). Asynchronous discussions and assessment in online learning.Journal of Research on Technology in Education, 39(3), 309-328. 